\title{
“Dragon and Bear": A SF-MDA Approach to Intersemiotic Relations
}

\author{
Hongmiao Gao ${ }^{1}$ \\ ${ }^{1}$ School of English for International Business, Guangdong University of Foreign Studies, China \\ Correspondence: Hongmiao Gao, School of English for International Business, Guangdong University of \\ Foreign Studies, Guangzhou, China. E-mail: 20160310016@gdufs.edu.cn
}

Received: May 1, 2017 Accepted: June 3, 2017 Online Published: July 26, 2017

doi:10.5539/ijel.v7n5p74 URL: http://doi.org/10.5539/ijel.v7n5p74

\begin{abstract}
Compared with analysing the meaning of discourse from the perspective of language only, multimodal discourse analysis embarking on modes like images, words, colour, sound and other elements can help understand the underlying meaning expressed more thoroughly. Systemic functional multimodal discourse analysis (SF-MDA) built upon systemic functional theory (SFT) is employed in this study. An illustrated article issued in The Economist is taken as an example to fully dredge the intersemiotic relations between the text and the image. By describing the text, interpreting and explaining the underlying sociocultural background of the countries involved, it functions to fully excavate the differences and problems faced by the two countries so that strategies can be defined to cope with the existent problems within. The study finds out that there is an intersemiotic complementarity between the verbal text and visual image. Hopefully, this paper can pave the way for the future research of intersemiotic relations between different modes.
\end{abstract}

Keywords: intersemiotic study, multimodal discourse analysis, Systemic Functional Grammar, Visual Grammar

\section{Introduction}

Systemic Functional Grammar (SFG) provides a sense of how the English grammar makes meaning in written and spoken text, illustrating the distinctive contributions made by the different options within a given system, thus exploring the relationship between grammar and discourse semantics (Halliday \& Matthiessen, 2004). Meanwhile, it also provides a foundational base for describing, explaining and interpreting multimodal discourses including language and other semiotic resources such as images, sound, gestures, colour, embodied action and so forth (e.g., Kress \& van Leeuwen, 2006; Jewitt, 2014). Hence, systemic functional multimodal discourse analysis (SF-MDA) approach (e.g., O'Halloran \& Lim-Fei, 2014) resulting from the combination of Systemic Functional Theory (SFT) and Multimodal Discourse Analysis (MDA) is increasingly employed in current researches.

In the beginning of the 1950s, after American linguist Harris (1952) put forward discourse analysis, many discourse analysts raised diversified theories and approaches in terms of this research orientation. However, those theoretical methods targeted language as the study object, and focused on the language system and the structure of semantics itself only, without consideration of effects from other semiotic modes like image, sound, colour, etc.

Until 1977, Barthes discussed the interaction of images and language in expressing meaning, which is the first time people were exposed to the conception of multimodality. In the 1990s, multimodal discourse analysis began to emerge and prevail in the West. O'Toole (1994) studied visual arts like painting, sculpture, architecture, etc. on the base of Applied Functional Linguistics theory, creating the pioneering work in studying multimodality. Kress \& van Leeuwen $(1996,2006)$ analysed and summarized visual grammar comprehensively and systematically based on the grammar foundation of SFG by Halliday (1985) and studied how image, sound, colour and other semiotic modes work together in the semantic construction in discourse, providing theoretical framework for multimodal discourse analysis. Multimodal Analysis has been applied to various fields and levels. For instance, O' Halloran (2004) not only put forward the theoretical construction of multimodality, but also extended the research to the multimodal phenomenon in Math; Royce (2002) explained the complementarity of different modes in multimodal discourse as well as the coordination of various modes functioning together in the teaching of a second language.

Surveying the recent annals of literature in SFL, some remarkable studies have been conducted to 
lexicogrammatically, attitudinally and rhetorically investigate three major sorts of meanings or meta-functions (Ideational, Interpersonal and Textual) as well as rhetoric in various texts and discourses to discern multiple strategies exploited by orators and authors in political, scientific, religious etc. (Cap \& Okulska, 2013; Kazemian et al., 2013; Kazemian \& Hashemi, 2014a, b; Noor et al., 2015; Zhou \& Kazemian, 2015; Kazemian \& Hashemi, 2017 etc.). In another vein, i.e. systemic functional multimodal discourse analysis, there are other salient studies dissecting and analysing meaning arising from the use of multiple semiotic resources in discourses which range from written, printed and electronic texts to material lived-in reality (Jewitt, Bezemer \& O’Halloran, 2015; Liang, 2014; O’Halloran, 2008; O'Halloran \& Lim-Fei, 2014; O' Halloran, Tan, \& Wignell, 2017; Royce \& Terry, 2007).

Prior studies have tended to concentrate on some other genres and discourses. This study is unique in the sense that it attempts to bridge the gap among previous studies by analysing illustrated article issued in The Economist as an example to fully dredge the intersemiotic relations between the text and the image, and it aims at answering the following three questions:

a. How does language realize its three meta-functions in the verbal text?

b. How does the image realize its three meanings in this caricature?

c. How do visual and verbal elements interact together in this illustrated article?

\section{Theoretical Framework}

According to Functional Grammar by Halliday (1985), language has three meta-functions: ideational function - expressing conceptual meaning; interpersonal function - displaying the relationship between speakers and listeners as well as the attitude of speakers towards what is talked about; textual function - explaining the meaning of the text or discourse. Functional Grammar is employed to analyse the verbal text of this illustrated article of "Dragon and Bear".

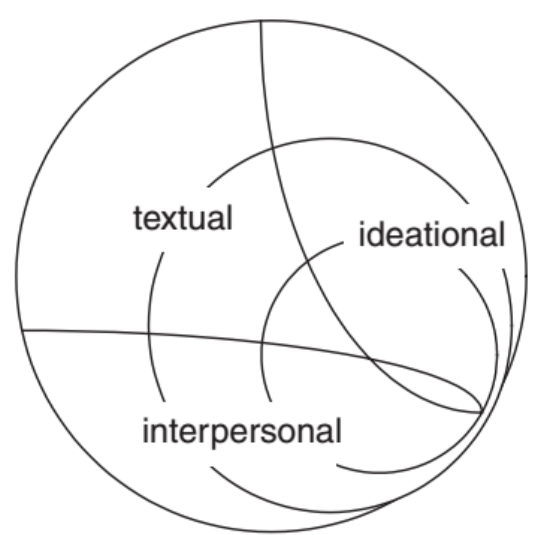

Figure 1. Three meta-functions of language (reproduced from Martin \& White, 2005, p. 12)

Visual Grammar (VG) proposed by Kress \& van Leeuwen (1996) was theorized on Halliday's Functional Grammar, claiming that the communicative system of human beings should not be limited to the single mode language, instead, other modes like image, sound, music, colour, etc. should also be employed with their own functions. Those meta-functions of language were applied to studies about visual grammar of images in the book, and specific terms were also found to match the functions of image-representational meaning, interactive meaning and compositional meaning in VG.

Representational meaning is that images can show us the actions of participants within, the internal relationship between them and their surrounding environment and what the participants are doing in a narrative or conceptual form. In the light of the characteristics of the image, the process of representation can be divided into narrative process and conceptual process. Narrative process displays the actions of participants and the events described with a focus on the development and change of the actions and the event as well as the placement of the elements in dimensional position within a short time; conceptual process has a less consideration of the time and more consideration of the class, status, role, inner qualities of the participants.

Interactive meaning explains that the nature of the image aims at arousing the interaction between the viewer and 
the designer or the interaction between the viewer and the participants depicted in the image. Three factors including distance, contact and attitude are crucial to realize the interaction, from which it can be reflected what kind of attitude the viewer should hold towards the represented things expected by the designers or what fact they want to display to the audience.

Compositional meaning consists in the placement and composition of elements, which depends on its information value, framing and salience. Information value is determined by the spatial position of elements in the whole, and to be placed in the left or the right, in the centre or the edge signifies different informational structures of different elements. Framing is determined by whether there is a split line in the picture. Salience shows the attention-attracting degree of the elements, which can be realized by the difference of position - the elements are placed in the foreground or the background, the relative size, colour contrast, saturation, etc.

\section{A Multimodal Discourse Analysis: An Uneasy Friendship}

\subsection{Analysis of the "Dragon and Bear" Caricature}

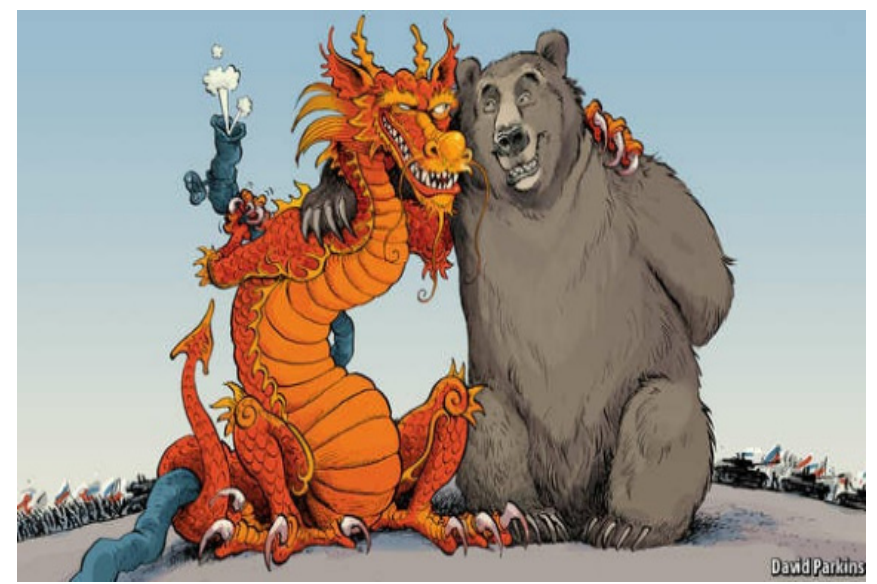

Figure 2. Dragon and Bear from the Economist 5/9/2015

\subsubsection{Representational Meaning}

\subsubsection{Narrative Representation Process}

Three action processes and two reactional processes can be found here. In action processes, the Actor is the participant from which the vector emanates, or which itself, in whole or in part, forms the vector that is usually a sharp diagonal line (Kress \& van Leeuwen, 2006, p. 63). In Figure 2, the vector in the first action process is the left hand of the dragon, connecting the dragon (the Actor) and the bear (the goal). Inversely, the behaviour of the hand of the bear (the Actor) being put on the shoulder of the dragon (the goal) is also an action process. Another action process can also be sought out, in which vector is the right hand or the tail of the dragon (the Actor), and the pipeline is the Goal. The eye line of the dragon (Reactor) looking at the bear (Phenomenon) forms a vector, as well, and vice versa, showing readers that they share a common goal and interest.

\subsubsection{Conceptual Representation Process}

It is symbolic processes that are to be focused on about what a participant means or is in this caricature. Apparently, the dragon and the bear are the Carriers of the image of China and Russia respectively. And the grab of the oil pipe by the dragon means that China hopes to take on the status of being the only importing country of Russia's newly exploited petroleum. On the background of the caricature, those China- and Russia-flagged naval vessels can be interpreted as that the two countries are going to conduct military exercise before long. Furthermore, the pipeline symbolizes Russia's petroleum resources with the water valve being the approach to get the resource; China holds tightly the priority to be the only importer of Russia's oil resources.

\subsubsection{Interactive Meaning}

The designing purpose of displaying an image is to realize the interaction between the image-producer and the viewers, informing them of the specific relationship between themselves and the hidden meaning so that they can interact with the producer. The interactive meaning of an image is realized by those four factors: contact, social distance, perspective and modality. 


\subsubsection{Contact}

In this "offer" image, neither the bear nor the dragon has a direct eye contact with the viewers. It presents the fact of the existing situation of Sino-Russia relationship with no tendency to interact with the viewers.

\subsubsection{Social Distance}

The choice between close-up, medium shot or long shot determines the relationship between the represented participants and viewers. Participants in the close shot symbolize the close relationship between the represented participants and the viewer; the long shot depicts that certain disparity exists between the two groups. In this caricature, represented participants are displayed in a medium long shot by showing the full figure of the dragon and the bear. In addition to the image of those two, there are many relatively much smaller naval vessels in the background and much blank space, implying the impersonal relationship between the image-producer and the viewer.

\subsubsection{Perspective}

To analyse from the horizontal angle, the front view shows a parallel perspective, connecting the image-producer with the viewer. Thus it can be seen that the relationship between China and Russia not only has an influence on the development of the two countries, but also is of paramount importance to the inter-relationship among different countries in the world. From the angle of horizontal level, the two animals appear to be tall and powerful, thus forming an upward view for the viewers. Intangibly, it brings symbolic authority to the viewers in order to force the viewer to clarify their attitudes toward the fact.

\subsubsection{Modality}

In the field of linguistics, the grammar of modality markers as the auxiliary verbs which accord specific degrees of modality to statements, verbs like may, will, must as well as their related adjectives (e.g., possible, probable, certain, etc.) and verbs. As well, the concept of modality is equally essential in accounts of visual communication. As to how to judge whether an image is real, "more than real" or "less than real", markers of naturalistic modality are put forward by Kress \& van Leeuwen, including colour saturation, colour differentiation, colour modulation, contextualization, representation, depth, illumination, brightness, etc.

Apparently, this caricature is produced with a sensory orientation used to delivery pleasure. Here, colour is an important modality marker when delivering pleasure and affective meanings. As for colour saturation, colour red and colour brown of full saturation is employed to depict the image of the bear and the dragon, using a high modality since colour red is a symbol of China. In terms of colour differentiation, a higher modality is also expressed with colours including red, brown, blue, black and white. Representation of pictorial details is clearly displayed by the sharp claws of the bear and the dragon as well as the thought-inspiring facial expressions.

\subsubsection{Compositional Meaning}

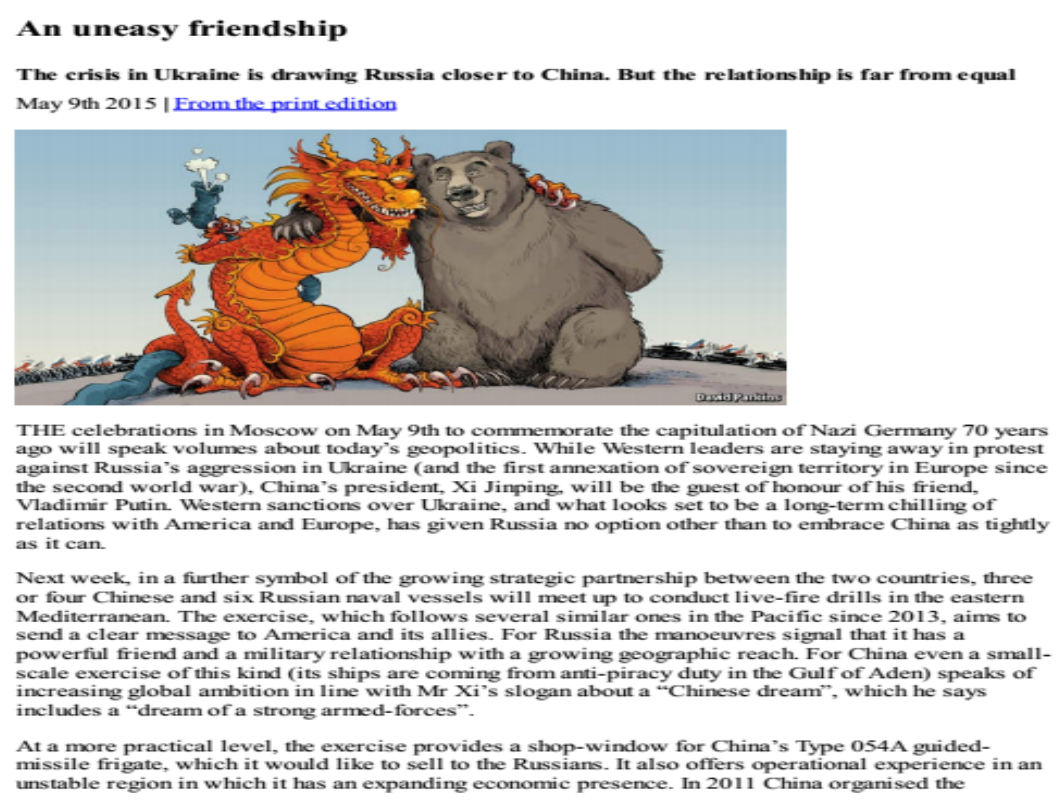

Figure 3. Verbal text 
The visual mode and verbal mode interact with each other to help readers better understand the theme of the text. The placement of the image at the beginning part aims at attracting the attention of the reader, which is very helpful to convey the topic.

\subsubsection{Information Value}

The role of participants depends on whether they are placed on the left or the right, on the centre or the edge and so on and so forth. The placement of the visual elements from the left to the right forms the structure of "from the known to the new" (Kress \& van Leeuwen op.cit.). In other words, information about the participants on the left is recognizable, while that on the right is unrecognizable. In the caricature of Sino-Russia relationship, it is clear that China has grabbed the channel to be accessible to Russia's natural resources, while attitudes of China towards Russia is still ambiguous.

\subsubsection{Salience}

Above all, the placement of the image at the beginning part prior to the verbal text simplifies and interprets the theme of the text. In terms of the image itself, nothing is more salient than the distinct display of the dragon and the bear that take most part of the space. Additionally, the image of the dragon with a relatively brighter colour than the bear better exemplifies the dominant role of China in the relationship. Although naval vessels in the background of the image represent the event of military exercise, it is not the topic to be highlighted.

\subsubsection{Framing}

The presence or absence of framing devices (realized by elements which create dividing lines, or by actual frame lines) disconnects or connects elements of the image, signifying that they belong or do not belong together in some sense. In the picture of Sino-Russia relationship, the arc formed by the naval vessels on the background split the combination of China and Russia from other countries.

\subsection{Analysis of the "Dragon and Bear" Text}

The semantic meaning of the text- the semantic unit and the product of semantic choices, is expressed through the realization of lexical-grammatical choices as well as systems of grammatical structure. The ideational strand of meaning (see Halliday \& Matthiessen, 2004) actually involves two components: that of experiential meaning and logical meaning. Experiential meaning is realized through the system of Transitivity, which is applied to analyse the ideational meaning expressed by clauses in the text.

\subsubsection{Ideational Meaning}

In the stance of ideational meaning of this verbal text, frequencies of various process types are counted through annotation of the transitivity system of the overall text. Among those processes, material processes take up the largest proportion, followed by relational processes and mental processes.

Most of the Intensive Identifying Processes are inserted in the last paragraph of the text, indicating its conclusive function. "Another difficulty is Russia's military and energy links with countries such as India and Vietnam, both of which are rivals of China. But the biggest problem of all may be Russia's irritation with being forced into an increasingly subservient role in its relations with China."

Table 1. Intensive identifying processes

\begin{tabular}{lll}
\hline Token & Pr: identifying & Value \\
\hline $\begin{array}{l}\text { Russia's military and energy links with countries such as India and Vietnam } \\
\text { both of which }\end{array}$ & is & $\begin{array}{l}\text { Another difficulty } \\
\text { rivals of China } \\
\text { Russia's irritation with being forced into an increasingly subservient role in } \\
\text { its relations with China }\end{array}$ \\
\hline
\end{tabular}

Through the examining of the Transitivity patterns, how the field of the situation is being constructed can be learned; what's being talked about can be naturally figured out. In the light of the precious analysis of Transitivity system of the text, the theme becomes more vivid together with the complement of the background information. Russia took back Crimea, bringing it hilarious victory as well as a more deteriorative relationship with Ukraine. American-led Western leaders published a series of sanctions towards Russia, making Russia's economy more staggering and tumbledown. At this critical juncture, Russia reached out to China, catalysing the agreement on military and petroleum cooperation. 


\subsubsection{Interpersonal Meaning}

The nature of language is to interact - to exchange information or to exchange goods or services. However, poles of "is" or "is not" are not the only possibilities when we are arguing about something, and degrees of probability in between are the normal choices-Modality.

In the verbal contents of the article, sentences of high modality like "China's president, Xi Jinping, will be the guest of honour of his friend, Vladimir Putin." and "it often holds counter-terrorism exercises with its SCO partners", expressing a high truth value of the cooperation China is going to make with Russia. And sentences of median modality like "In every instance it is probable that China was able to drive a hard bargain on price." as well as "But the biggest problem of all may be Russia's irritation with being forced into an increasingly subservient role in its relations with China." Probable and may express a lower modality, signifying that those sentences containing modality are not for sure actually. Lastly, sentences of low modality like "Russia's natural resources, at favourable prices, as well as to secure access to big infrastructure contracts that might have gone to Western competitors and to provide financing for projects that will benefit Chinese firms." Might is used here to express the uncertainty involved, thus inviting interaction from the viewers.

Similar to modalization (expressing possibility, frequency), degrees of modulation (obligation, inclination and necessity) can also be classified into three: high (must/required to), median (should/supposed to), low (may/allowed to). Such as "Striking evidence of the new closeness between China and Russia was a $\$ 400$ billion gas deal signed in May last year under which Russia will supply China with 38 billion cubic metres (BCM) of gas annually from 2018 for 30 years." Here, "will" expresses the obligation and willingness of Russia to supply China with gas according to the agreement which has already been signed by the two parties. "At a more practical level, the exercise provides a shop-window for China's Type 054A guided missile frigate, which it would like to sell to the Russians." Compared with the former sentence, this one is of low modality by employing "would like", representing that whether China will sell its Type 054A guided missile frigate is an outstanding issue.

Declarative mood displaying facts is more easily to be found after a thorough examining of the whole text. Sentences of modality can also be easily found out with an underlying meaning that there are still a lot to be figured out about the relationship between China and Russia. The interpersonal meaning expressed by modality is to attract the attention and to inspire the opinions of viewers.

\subsubsection{Textual Meaning}

The textual meaning, is described as the "relevance" or the "enabling" metafunction to make effective the context and the purpose through the ordering of constituents (Eggins, 2004). The system of Theme is elaborated here, which is realized through a structure falling into two main constituents: a Theme and a Rheme. Theme is the element which serves as "the starting-point for the message: it is what the clause is going to be about". Rheme is everything that is not the Theme (Halliday \& Matthiessien op.cit.).

Through the annotation of the whole text, frequencies of various categories of thematic choices are listed out as follows,

Table 2. Theme

\begin{tabular}{ll}
\hline Theme & \\
\hline Thematic choices & Frequency \\
Marked Theme & 20 \\
Topic Theme & 45 \\
Textual Theme & 11 \\
Interpersonal Theme & 2 \\
Ranking clause & 71 \\
\hline
\end{tabular}

Marked Theme is when Theme conflates with any other constituent from the Mood system. The commonest type is that conflating with an Adjunct: circumstantial. When a marked choice is made, the speaker/writer is indicating that something in the context requires an unusual meaning to be made. And skilful writers and speakers choose marked Themes to add coherence and emphasis to their text. From Table 2, it can be concluded that marked Theme takes a large proportion here in this illustrated article. Therefore, the proficiency of the writers of The Economist is visible. For the sake of the mode as a written text, this article selected uses a tiny proportion of choices of interpersonal Theme. 
Therefore, it can be concluded that text can only be realized through the combination of the functional-semantic approach of language--ideational, interpersonal and textual meaning.

\subsection{An Intersemiotic Study on the Image and the Text}

To perceive the essence by seeing through the appearance, multimodal discourse analysis (MDA) can be employed. SFG is used here to analyse different meanings expressed by the verbal text and VG is also applied to interpret the meanings conveyed by the visual image.

Table 3. Comparison between VG and SFG (Based on Kress \& van Leewen 1996; Eggins 2004)

\begin{tabular}{ll}
\hline VG & SFG \\
\hline Representational meaning & Ideational meaning \\
Interactive meaning & Interpersonal meaning \\
Compositional meaning & Textual meaning \\
\hline
\end{tabular}

Highlighting of the image of the dragon and the bear exactly presents the theme "An Uneasy Friendship". Meanwhile, to fully understand the verbal text is of paramount importance to comprehend the main idea and the key tone of the article. Representational meaning of the image in VG quotes the ideational meaning, specificly the experiential function of language in SFG. And experiential function is expressed through the system of transitivity or process type, with the choice of process implicating associated participants roles and configurations. The matchup is displayed in Table 3.

To figure out the relationship between the image and the verbal text is of vital importance in intersemiotic studies when analysing an illustrated article. Visual modes and verbal structures can be used to express meanings drawn from a common culture source and they are alternative means of representing "the same thing".

\subsubsection{Comparison of Representational Meaning in Image and Ideational Meaning in Verbal Text}

Those three action processes and two reactional processes represented in the caricature can be projected into 5 material processes and 3 mental processes of transitivity in the text, which are listed and annotated in Table 4 and Table 5. And the represented participants of the dragon, bear and the pipeline are equivalences to China, Russia and natural resources in the verbal text.

Table 4. Material processes in dragon $\&$ bear text

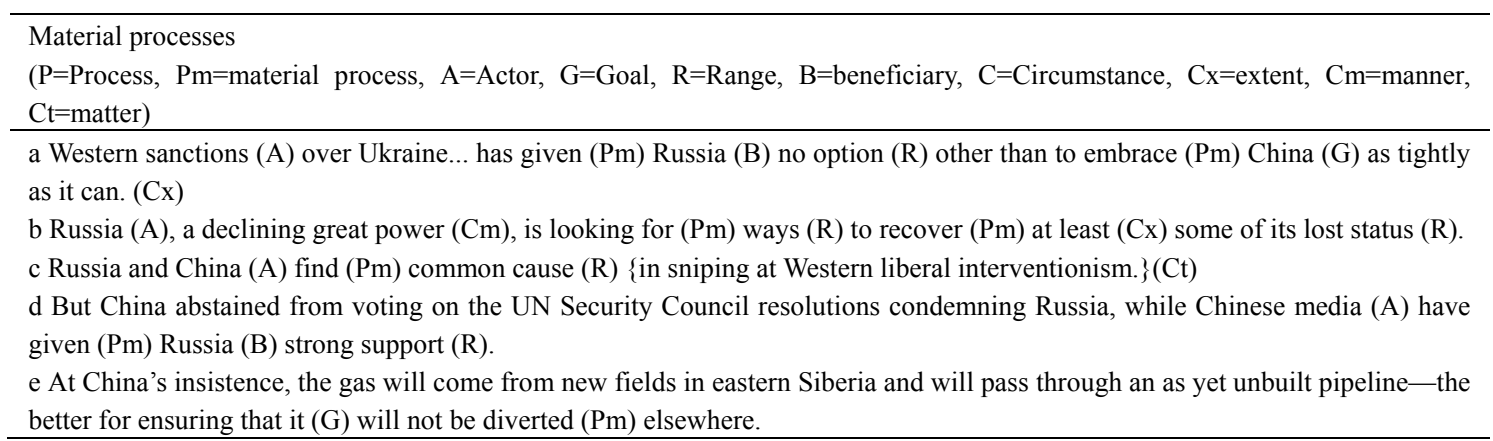

The examining of the transitivity system in the verbal text can, on the one hand, help the viewer better understand semantically based on a deeper look at the lexicogrammar, and on the other hand, make explicit the overall meaning co-expressed by both the text and the image. The first action process of putting the dragon's left hand on the bear's shoulder is correspondent to the verbal part of Table 4 (d) - China turned a blind eye to Russia's behaviour when it is condemned by the UN Security for Russia's intrusion into Ukraine. The second action process initiated by the bear mirrors the sentences like Table 4 (a) and (b) - Russia regards China as a life-saving straw at this moment. Table 4 (c) is also represented by the two standing-by-together animals. The third action process of the grabbing the pipeline by the dragon can find its corresponding verbal part-Table 4 (e). 
Table 5. Mental processes in Dragon \& Bear Text

\begin{tabular}{l}
$\begin{array}{l}\text { Mental processes } \\
\text { (Pme=mental process, } \mathrm{S}=\text { Senser, } \mathrm{Ph}=\text { Phenomenon) }\end{array}$ \\
\hline a At a more practical level, the exercise provides a shop-window for China's Type 054A guided missile frigate, which it (S) \\
would like (Pme) \{to sell to the Russians $\}.$ \\
b Russia (S) \{is also wary\}(Pme) \{of becoming little more than a supplier of natural resources to China's industrial machine. (Ph) \\
c Mr Putin(S) wants (Pme) \{to establish his Eurasian Economic Union partly to counter growing Chinese economic power in \\
Central Asia , through which China (S) wants (Pme) \{to develop what it calls a Silk Road Economic Belt.
\end{tabular}

In a similar way, the two reactional processes could also be projected into three mental processes of verbal clauses analysed from the angle of SFG as listed in Table 5. The underlying meaning of sharp eyes and the cunning smile of the dragon is that China seems to be purposeful to take part with Russia.

However, compared with the relational processes, existential processes occupies a relatively small number (only two), which signifies that the relationship is not established and invariable as friendly all the time, instead, it can be situation-dependent or it is not what it looks like.

\subsubsection{Comparison of Interactive Meaning in Image and Interpersonal Meaning in Verbal Text}

Both the image and the verbal text have referred to modality by using colour with high saturation, differentiation and clear representation of pictorial details, and adopting many modality markers in the verbal text, like may be, often, possible, probable, must etc. However, the use of any modality at all, however strong it appears, make our proposition more tentative than it would be without modality (Eggins ibid., p. 175).

\subsubsection{Comparison of Compositional Meaning in Image and Textual Meaning in Verbal Text}

Through the annotation of Theme choices of the whole text, the topic themes which display given information can be classified into the above categories - China, Russia, the relationship and cooperation between the two, background information as well as time and location. From the data, much more information is about the fact of cooperation and relationship between China and Russia, and the background information including time and location, while attitude held by China and Russia is relatively less. Therefore, it is consistent with the information represented by the image. In the verbal text, we can learn that the attitude held by Russia toward China is almost about worry and defence, while it is still hard to define what kind of attitude China holds toward Russia both from the image and the text.

There is some affinity and consistency between visual modes and verbal modes, especially when they are employed to narrate the same topic. But they are essentially different in that the visual semiotic has a range of structural devices which have no equivalent in language.

\section{Conclusion}

This paper uses SF-MDA approach to analyse the structural characteristics of discourse from the semantic level, and employs VG to decode the underlying meaning of the image which is correspondent and complementary to the verbal text. Therefore, to unveil the literal meaning of the discourse imposed by the language-users is of vital importance to further confirm the credibility and authenticity of the subject.

However, there are also some limitations of this study due to lack of time and personal capability. Meanwhile, the ambiguity and overlapping of some process types of SFL contributes to space to improve the analysis of the image and the text of "Dragon and Bear". Additionally, this paper makes multimodal discourse analysis of only one illustrated article selected from The Economist, taking only modes of image and words into consideration. Hopefully, the explanatory approach and process of this illustrated article can serve as a modest spur in English Language Teaching and in future researches, the theories used can be applied to other fields for the latecomers and the conclusions summarized can be useful to the future development of China and China's diplomatic relations.

\section{Acknowledgments}

The author is deeply indebted to her supervisor Chunyu Hu for his critical suggestions on the manuscript.

\section{References}

Barthes, R. (1977). Image music text. London: Fontana Press.

Cap, P., \& Okulska, U. (Eds.). (2013). Analyzing genres in political communication: theory and practice (Vol. 50). Amsterdam: John Benjamins Publishing. 
Eggins, S. (2004). An Introduction to Systemic Functional Linguistics (2nd ed.). London: Continuum.

Fairclough, N. (1995). Critical discourse analysis. New York: Longman Publishing.

Halliday, M. (1985 /1994). An Introduction to Functional Grammar. London: Arnold Publishers.

Halliday, M. (2001). Language as Social Semiotics: The Social Interpretation of Language and Meaning. Beijing: Foreign Language Teaching and Research Press.

Halliday, M., \& Matthiessen, C. (2004). An Introduction to Systemic Functional Linguistics (3rd ed). London: Arnold Publishers.

Harris, Z. (1952). Discourse Analysis. Language, 28(1), 1-30. (Reprinted in Papers on Syntax, pp. 107-142, 1981.)

Jewitt, C. (Ed.) (2014). The Routledge handbook of multimodal analysis. London: Routledge.

Jewitt, C., Bezemer, J., \& O’Halloran, K. L. (Eds.). (2015). Introducing multimodality. London: Routledge.

Kazemian, B., \& Hashemi, S. (2014a). Nominalizations in scientific and political genres: A systemic functional linguistics perspective. International Journal of Humanities and Social Sciences (IJHSS), 3(2), 211-228.

Kazemian, B., \& Hashemi, S. (2014b). Critical discourse analysis of Barack Obama's 2012 speeches: Views from systemic functional linguistics and rhetoric. Theory and Practice in Language Studies (TPLS), 4(6), 1178-1187. http://dx.doi.org/10.4304/tpls.4.6.1178-1187

Kazemian, B., \& Hashemi, S. (2017). A Radical Shift to a Profound and Rigorous Investigation in Political Discourse: An Integrated Approach. International Journal of English Linguistics, 7(3), 115-128. https://doi.org/10.5539/ijel.v7n3p115

Kazemian, B., Behnam, B., \& Ghafoori, N. (2013). Ideational grammatical metaphor in scientific texts: a Hallidayan perspective. International Journal of Linguistics, 4(4), 146-168. http://dx.doi.org/10.5296/ijl.v5i4.4192

Kress, G., \& Hodge, R. (1979). Language as Ideology. London: Routledge and Kegan Paul.

Kress, G., \& van Leeuwen, T. (1996/2006). Reading Images: The Grammar of Visual Design (2nd ed.). London: Routledge.

Liang, E. (2014). Gender difference in sports advertisements and its teaching implications: a systemic functional multimodal discourse analysis (SF-MDA) approach. Cross-Cultural Communication, 10(2), 62-80. http://dx.doi.org/10.3968/\%25x

Martin, J., \& White, P. R. (2005). The language of evaluation: appraisal in English. New York: Palgrave Macmillan.

Noor, M., Ali, M., Muhabat, F. \& Kazemian, B. (2015a). Systemic Functional Linguistics Mood Analysis of the Last Address of the Holy Prophet (PBUH). International Journal of Language and Linguistics. Special Issue: Critical Discourse Analysis, Rhetoric, and Grammatical Metaphor in Political and Advertisement Discourses, 4(1-1), 1-9. http://dx.doi.org/10.11648/j.ijll.s.2015030501.11

O’ Halloran, K. L., Tan, S., \& Wignell, P. (Eds.). (2017). SFL and Multimodal Discourse Analysis (in press). Cambridge: Cambridge University Press.

O'Halloran, K. L. (2005). Mathematical Discourse: Language, Symbolism and Visual Image. London: Continuum.

O’Halloran, K. L. (2008). Systemic functional-multimodal discourse analysis (SF-MDA): constructing ideational meaning using language and visual imagery. Visual Communication, 7(4), 443-475. http://dx.doi.org/10.1177/1470357208096210

O’Halloran, K. L. (Ed.). (2004). Multimodal Discourse Analysis: Systemic-Functional Perspectives. London: Continuum.

O’Halloran, K. L., \& Lim-Fei, V. (2014). Systemic functional multimodal discourse analysis. In S. Norris \& D. M. Carmen (Eds.), Texts, images and interactions: a reader in multimodality (pp. 137-153). Berlin: Mouton de Gruyter.

O’Toole, M. (1994). The language of displayed art. London: Leicester University Press.

Royce, T. (1998/2002). Exploring intersemiotic complementarity in page-based multimodal text. Tokyo: Japan Association of Systemic Functional Linguistics. 
Royce, T. (2007). Intersemiotic complementarity: a framework for multimodal discourse analysis. In T. Royce, \& W. Bowcher (Eds.), New directions in the analysis of multimodal discourse (pp. 63-110). T. Mahwah NJ: Lawrence Erlbaum Associates.

van Leeuwen, T. (2008). Discourse and Practice: New tools for Critical Discourse Analysis. New York: Oxford University Press, Inc.

Zhou, Q., \& Kazemian, B. (2015). A Rhetorical Identification Analysis of English Political Public Speaking: John F. Kennedy's Inaugural Address. International Journal of Language and Linguistics. Special Issue: Critical Discourse Analysis, Rhetoric, and Grammatical Metaphor in Political and Advertisement Discourses, 4(1-1), 10-16. http://dx.doi.org/10.11648/j.ijll.s.2016040101.12

\section{Note}

Note 1. This article of "Dragon and Bear" is taken from The Economist (May 9th 2015, pp. 92-94). Source URL: http://www.economist.com/business-finance.

\section{Copyrights}

Copyright for this article is retained by the author(s), with first publication rights granted to the journal.

This is an open-access article distributed under the terms and conditions of the Creative Commons Attribution license (http://creativecommons.org/licenses/by/4.0/). 